\title{
Direct Peptide Profiling of Lateral Cell Groups of the Antennal Lobes of Manduca sexta Reveals Specific Composition and Changes in Neuropeptide Expression during Development
}

\author{
Sandra Utz, ${ }^{1}$ Wolf Huetteroth, ${ }^{1}$ Christian Wegener, ${ }^{1,2}$ Jörg Kahnt, ${ }^{3}$ \\ Reinhard Predel, ${ }^{4}$ Joachim Schachtner ${ }^{1}$ \\ ${ }^{1}$ Fachbereich Biologie, Tierphysiologie, Philipps Universität, Karl-von-Frisch-Straße, \\ D-35032 Marburg, Germany \\ 2 Emmy Noether Neuropeptidgruppe, FB Biologie, Tierphysiologie, Philipps-Universität, \\ Karl-von-Frisch-Straße, D-35032 Marburg, Germany \\ ${ }^{3}$ Max Planck Institut für terrestrische Mikrobiologie, Karl-von-Frisch-Straße, D-35043 Marburg, Germany \\ ${ }^{4}$ Institut für Allgemeine Zoologie und Tierphysiologie, Friedrich-Schiller-Universität, \\ Ebertstraße 1, Jena D-07743, Germany
}

Received 24 September 2006; revised 13 December 2006; accepted 14 December 2006

\begin{abstract}
The paired antennal lobes are the first integration centers for odor information in the insect brain. In the sphinx moth Manduca sexta, like in other holometabolous insects, they are formed during metamorphosis. To further understand mechanisms involved in the formation of this particularly well investigated brain area, we performed a direct peptide profiling of a well defined cell group (the lateral cell group) of the antennal lobe throughout development by MALDI-TOF mass spectrometry. Although the majority of the about 100 obtained ion signals represent still unknown substances, this first peptidomic characterization of this cell group indicated the occurrence of 12 structurally known neuropeptides. Among these peptides are helicostatin 1 , cydiastatins 2,3 , and $4, M$. sexta-allatotropin (Mas-AT), M. sexta-FLRFamide (Mas-FLRFamide) I, II, and III, nonblocked Mas-FLRFamide I, and M. sextamyoinhibitory peptides (Mas-MIPs) III, V, and VI. The identity of two of the allatostatins (cydiastatins 3 and 4 ) and Mas-AT were confirmed by tandem mass spectrometry
\end{abstract}

This article contains supplementary material available via the Internet at http://www.interscience.wiley.com/jpages/1932 8451/ suppmat. de)

Correspondence to: J. Schachtner. (schachtj@staff.uni marburg.
(MALDI-TOF/TOF). During development of the antennal lobe, number and frequency of ion signals including those representing known peptides generally increased at the onset of glomeruli formation at pupal Stage P7/8, with cydiastatin 2, helicostatin 1 , and Mas-MIP $\mathrm{V}$ being the exceptions. Cydiastatin 2 showed transient occurrence mainly during the period of glomerulus formation, helicostatin 1 was restricted to late pupae and adults, while MasMIP V occurred exclusively in adult antennal lobes. The power of the applied direct mass spectrometric profiling lies in the possibility of chemically identifying neuropeptides of a given cell population in a fast and reliable manner, at any developmental stage in single specimens. The identification of neuropeptides in the antennal lobes now allows to specifically address the function of these signaling molecules during the formation of the antennal lobe network. (c) 2007 Wiley Periodicals, Inc. Develop Neurobiol 67: 764-777, 2007

Keywords: MALDI-TOF mass spectrometry; insect; metamorphosis; olfactory system 

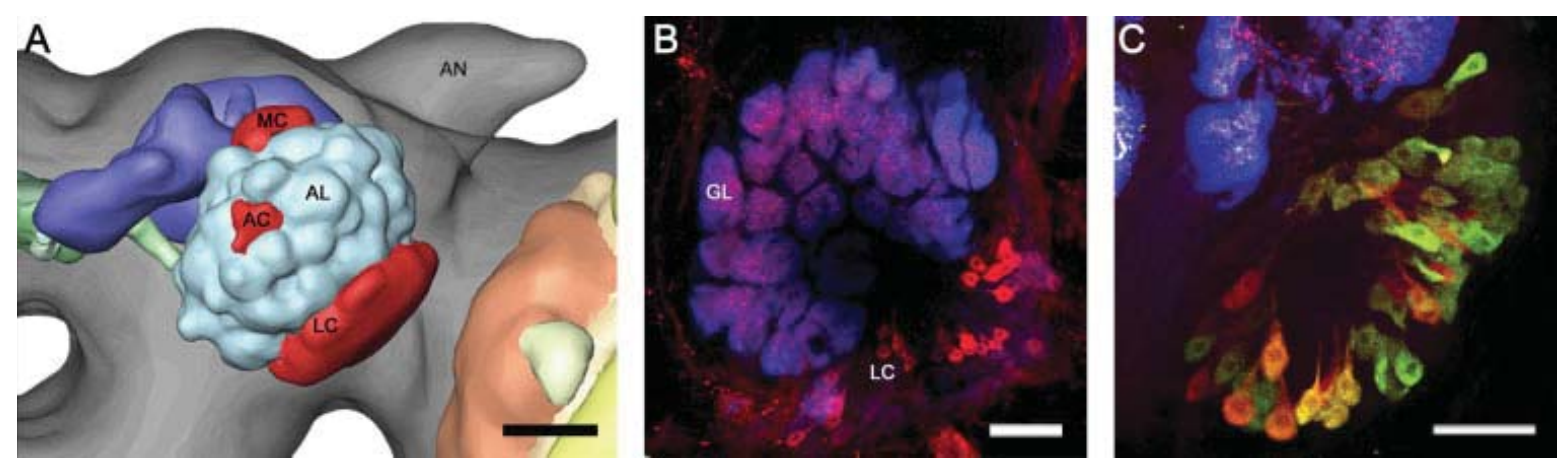

Figure 1 Antennal lobe (AL) morphology of Manduca sexta. (A) 3D reconstruction of a female left antennal lobe (AL, light blue) with respect to the localization of the three cell groups: anterior (AC), median (MC) and lateral (LC) cell group (all red). The AL is situated at the front of the brain (gray), anterior to the mushroom body (blue) and the central complex (green) and median to the neuropils of the optic lobe (orange/yellow). It receives its sensory input via the antennal nerve (AN, gray), which enters the brain laterodorsally. Scale: $200 \mu \mathrm{m}$. (B) Anti myoinhibitory peptide antiserum (MIP ir, red) labels a subpopulation of neurons in the lateral cell group (LC) at stage P17. According to their morphology, these cells are mainly local interneurons innervating the antennal neuropil, which is organized in about 60 olfactory glomeruli (GL). Glomeruli were visual ized with an antiserum against the presynaptic vesicle protein synapsin (blue) (scale: $80 \mu \mathrm{m}$ ). (C) Immunostaining with antisera against the neuropeptides Mas AT (green) and Dip AST7 (red) also labels subpopulations of neurons of the lateral cell group, here at stage P12. Glomeruli were visual ized with an antiserum against the presynaptic vesicle protein synaptotagmin (blue), scale: $80 \mu \mathrm{m}$.

\section{INTRODUCTION}

The antennal lobes (ALs) of the sphinx moth Manduca sexta serve as a well established model for the development of the olfactory system (Fig. 1; Hildebrand et al., 1997; Tolbert et al., 2004). ALs represent the primary integration centers for odor information in the insect brain and are compared to the olfactory bulb of vertebrates (Strausfeld and Hildebrand, 1999; Eisthen, 2002). AL and the olfactory bulb share not only their principal morphological organization into the so-called olfactory glomeruli, but also a number of basic physiological properties with respect to information processing (Hildebrand and Shepherd, 1997). Another characteristic of AL and the olfactory bulb is the expression of a variety of neuropeptides (Smith et al., 1993; Caillol et al., 2003; Moody and Merali, 2004; Gutierrez-Mecinas et al., 2005; Schachtner et al., 2005).

The ALs of $M$. sexta arise during $\sim 3$ weeks of hormonally-controlled pupal development (named pupal stages P0 to P20; Truman, 1996; Schachtner et al., 2004b). During this time, the whole brain undergoes reorganization and paired small larval antennal centers develop into the adult ALs (for reviews, see Oland and Tolbert, 1996; Tolbert et al., 2004). AL development in M. sexta can roughly be divided into three phases and, in contrast to other developing brain areas, no programmed cell death occurs (Dubuque et al., 2001; Schachtner et al., 2004a). During phase I which lasts from stage P0 to $\mathrm{P} 7 / 8$, the neuronal components of the ALs are provided all neurons are born until stage P3, olfactory receptor neurons start to grow into the forming $\mathrm{AL}$ neuropil from $\mathrm{P} 4$ on, and the glomerular templates are formed between stages P6 and P7/8 (Hildebrand, 1985; Hildebrand et al., 1997; Oland et al., 1998). Phase II (P7/8 to P12/13) the phase of glomeruli formation is characterized by massive synaptogenesis between the involved neurons (Oland and Tolbert, 1996; Dubuque et al., 2001). It is assumed that at the end of phase II the principal network within and between glomeruli has formed (Dubuque et al., 2001). During phase III (P12/13 to adult eclosion) the main wave of synaptogenesis has ceased but the glomeruli grow in size, probably because of the increasing neurite diameters (Tolbert et al., 1983; Tolbert, 1989; Dubuque et al., 2001; Huetteroth and Schachtner, 2005). During this last phase, the synaptic connections in the glomeruli are thought to undergo further maturation and refinement (Tolbert et al., 1983; Dubuque et al., 2001).

Immunocytochemical studies in a diversity of insects have indicated that several neuropeptides, 
including members of FMRFamide-related peptides (FaRPs), allatotropin, and allatostatins are present in subpopulations of local AL neurons, which are responsible for information processing within and between glomeruli (for review see Schachtner et al., 2005; Fig. 1). Neuropeptides might operate as cotransmitters of GABA ( $\gamma$-aminobutyric acid), the principle transmitter of local AL interneurons (Homberg and Müller, 1999). Concerning AL neurochemistry, the ALs of M. sexta are among the best studied (for review see Schachtner et al., 2005). The cellular location and temporal occurrence of certain neuropeptides during ontogeny of the ALs of M. sexta have also been mapped by immunolabeling. Interestingly, each of the studied peptide families, including FaRPs, A-type allatostatins, and allatotropins revealed a unique developmental acquisition pattern in defined sets of AL neurons. The occurrence of these neuropeptides is developmentally regulated by the steroid hormone 20-hydroxyecdysone. For each neuropeptide family, the temporal pattern of their occurrence correlates with defined developmental phases, suggesting defined roles during AL development, including formation of olfactory glomeruli (Schachtner et al., 2004b; Utz and Schachtner, 2005; Utz et al., 2005).

In insects, peptides often occur in multiple isoforms within one neuropeptide family and members of the same family are usually encoded by the same gene (e.g., Vanden Broeck, 2001; Riehle et al., 2002; Predel et al., 2004; Hummon et al., 2006), but chemical identification of different isoforms by immunocytochemical methods is nearly impossible. The aim of the present study was first to determine the neuropeptidome of the AL, and second to reveal whether different isoforms are expressed during different times of development. For this purpose, direct peptide profiling of a defined neural cell cluster of individual moths by matrix-assisted laser desorption/ionization time of flight mass spectrometry (MALDI-TOF-MS) is an excellent tool to demonstrate the occurrence of such isoforms and their potential differential expression pattern during metamorphosis, which has not been reported so far. Recently, peptide fragmentation with tandem mass spectrometry parallel to the standardized MALDI-TOF-MS has emerged as an additional tool which provides enhanced capabilities for peptide sequencing directly from samples such as nervous tissues or even single cells of invertebrates, including those of insects (e.g., Yew et al., 2003; Billimoria et al., 2005; Neupert and Predel, 2005; Nachman et al., 2006; Wegener et al., 2006). This study is the first attempt to chemically describe developmentdependent peptide expression in an identified neuronal cell cluster within a defined brain region, the AL.

\section{MATERIALS AND METHODS}

\section{Insects}

Manduca sexta (Lepidoptera: Sphingidae) were raised on ar tificial diet under long day photoperiod (L:D $=17: 7)$ at $26^{\circ} \mathrm{C}$ in walk in environmental chambers (Bell and Joachim, 1978). Under these conditions, approximately 21 days were required from pupal to adult ecdysis. Newly formed pupae are designated as P0. Subsequent days of pupal development are counted as P1 to P20. Larvae and pupae were staged according to the criteria described by Jindra et al. (1997) and Schwartz and Truman (1983). The criteria involve changes in structures that are either superficial or readily visible through the pupal cuticle under a dissecting microscope.

\section{MALDI-TOF Mass Spectrometry}

To selectively obtain identified cell groups, we first detached ALs from isolated brains by pulling the antennal nerve and the attached AL in an anterior direction and then by cutting the ball shaped AL off the protocerebrum with a pair of fine scissors. This technique ensured selective re moval of the AL with no or negligible contamination by protocerebral tissue. The larger lateral and the smaller medial cell group can easily be distinguished on the surface of the isolated ALs. The cell groups were selectively peeled off from the underlying central neuropil by using ultra fine scissors and microneedles, and were transferred onto a stainless steel sample plate for MALDI TOF MS. All steps until tissue transfer onto sample plates were performed rapidly in cold saline (Weevers, 1966). After air drying the tissue, the spots were covered with pure water for a few seconds, which was removed by cellulose paper. Approxi mately $50 \mathrm{~nL}$ matrix solution (recrystallized $\alpha$ cyano 4 hydroxycinnamic acid dissolved in methanol/ $\mathrm{H}_{2} \mathrm{O} / \mathrm{TFA}$ (tri fluoroacetic acid); 60/39/1; v/v/v for stage P1 to P10 and ACN (acetonitril)/ $\mathrm{H}_{2} \mathrm{O} / \mathrm{TFA} ; 70 / 29 / 1$; v/v/v or methanol/ ethanol $/ \mathrm{H}_{2} \mathrm{O} / \mathrm{TFA}$; 30/30/39/1 for stage P11 adult) was pumped onto the dried preparations using a nanoliter injec tor (Neupert and Predel, 2005). Each preparation was allowed to dry again and was then covered with $0.1 \%$ TFA for a few seconds, which was removed by cellulose paper. Mass analyses were obtained using a Voyager DE MALDI TOF biospectrometry workstation (PerSeptive Biosystems, Framingham, MA). Samples were analyzed in positive reflectron mode in the mass range of $8303000 \mathrm{Da}$. Syn thetic peptides were used for external calibration (angioten $\sin$ I, $1296.7 \quad[\mathrm{M}+\mathrm{H}]^{+}$; $\quad$ ACTH (clip 1 17), 1093.1 $\left.[\mathrm{M}+\mathrm{H}]^{+}\right)$. The ion signals of cydiastatin $3\left(925.5[\mathrm{M}+\mathrm{H}]^{+}\right)$ or cydiastatin $4\left(909.5[\mathrm{M}+\mathrm{H}]^{+}\right)$and Mas AT $(1486.7$ $[\mathrm{M}+\mathrm{H}]^{+}$) were later used for internal calibrations. For tan dem MS experiments, analyses were performed on an Ultra flex TOF/TOF (Bruker Daltonics, Bremen, Germany) equipped with LIFT technology. Because of the limited na ture of the samples, all acquisitions were taken in manual mode. To determine parent masses, the instrument was operated in reflectron mode prior to fragmentation. The fragmentation data obtained in these experiments were 
handled using the flexAnalysis software package (Bruker Daltonics, Bremen, Germany).

\section{Immunocytochemistry}

For immunostaining in the $\mathrm{AL}$ of $M$. sexta, rabbit anti sera against $M$. sexta allatotropin (Mas AT), Diploptera allatostatin 7 (Dip AST7), Periplaneta americana myoin hibitory peptide (Pea MIP), and monoclonal antibodies from mouse against two ubiquitous synaptic vesicle pro teins from Drosophila namely synaptotagmin and synap sin I (SYNORF1) were used. Antiserum against Mas AT was used at a concentration of 1:4000 (No. 13.3.91, kindly provided by Dr. J. Veenstra, University of Bor deaux, Talence, France; Veenstra and Hagedorn, 1993). The antiserum recognizes Mas AT (Kataoka et al., 1989) and Locusta myotropin (Veenstra and Hagedorn, 1993), both ending with TARGFamide. Specificity of the anti Mas AT antiserum has been shown by preadsorption of the antiserum with $100 \mu M$ synthetic Mas AT (Bachem) for $1 \mathrm{~h}$ at room temperature, which abolished all immuno staining in $M$. sexta brain sections (data not shown). Pre adsorption of the antiserum with $100 \mu M$ synthetic FLRFamide, FMRFamide, or Dip AST 7 (all Sigma) for $1 \mathrm{~h}$ at room temperature had no effect on immunostain ing (data not shown). Antiserum against Dip AST7 was used at a concentration of 1:10,000 (kindly provided by Dr. H. Agricola, University of Jena, Germany; Utz and Schachtner, 2005). Competitive ELISA showed that the serum cross reacts with other members of the A type allatostatin family of peptides characterized by a Y/ FXFGLamide C terminus (Vitzthum et al., 1996). The antiserum against Pea MIP (1:3000, kindly provided by Dr. M. Eckert, University of Jena, Germany) is thought to generally recognize myoinhibitory peptides. Pread sorption experiments and competitive ELISA showed that the anti Pea MIP antiserum recognizes myoinhibi tory peptides, but not Pea adipokinetic hormones $\mathrm{C}$ ter minally ending with NWamide (Predel et al., 2001; Eck ert and Wegener, unpublished). Anti synaptotagmin (1:4000, kindly provided by Dr. K. Menon, Caltech) and anti synapsin antibodies (1:100, kindly provided by Dr. E. Buchner, University of Würzburg, Germany) were used to selectively label neuropil structures including ol factory glomeruli (Dubuque et al., 2001; Berg et al., 2002).

Goat anti rabbit antibodies conjugated to $\mathrm{Cy} 2$ and $\mathrm{Cy} 3$, and goat anti mouse antibodies conjugated to Cy5 were used as secondary antisera (each 1:300; JacksonImmuno Research, Westgrove, PA). After dissection in cold saline (Weevers, 1966), the brains of M. sexta were fixed in 4\% formaldehyde in phosphate buffered saline overnight at $4^{\circ} \mathrm{C}$. After fixation, the brain was either embedded in gela tin/albumin, postfixed overnight in $4 \%$ buffered formalde hyde and cut at $40 \mu \mathrm{m}$ with a vibrating blade microtome (Leica VT 1000S) in the frontal plane, or processed as wholemount. Immunostaining procedure was performed exactly as described in Schachtner et al. (2004b) or, for the wholemounts, as described in Huetteroth and Schachtner
(2005) and fluorescence analyzed using a confocal laser scan microscope (Leica TCS SP2). Double labeling with anti Mas AT and anti Dip AST7 antisera was performed according to a method modified from Negoescu et al. (1994), for double immunolabeling with primary antisera from the same species as recently described in Berg et al. (2006).

\section{RESULTS}

Neurons of the $M$. sexta ALs are organized in three distinct cell groups [Fig. 1(A)]. This anatomical organization allowed the selective removal of the two larger cell groups for direct mass spectrometric profiling. The lateral cell group with about 980 somata contains a mixed population of local and projection neurons, while the median cell group contains only projection neurons (about 200 somata; Homberg et al., 1988). Immunostainings with antisera recognizing C-terminal sequences characteristic of several neuropeptide families (including A-type allatostatins, Mas-allatotropin, RFamides, and myoinhibitory peptides) revealed somata localized in the lateral cell group but not in the other two cell groups [Fig. 1(B C); Schachtner et al., 2004b; Utz and Schachtner, 2005; Utz et al., 2005].

Direct peptide profiling of lateral cell group preparations revealed a total of about 100 different ion signals during pupal development and in the adult (see Fig. 2), with a maximum of over 50 different masses in single spectra of lateral cell groups of animals of stage P8 or older. Signal intensity obtained was overall small in comparison with other studies in which direct profiling of arthropod tissue or single neurons was performed (e.g. Ma et al., 2000; Predel et al., 2004; Neupert and Predel, 2005). At the beginning of this study, we encountered massive problems to obtain ion signals of peptides by direct mass profiling and had to test various combinations of solvents with the $\alpha$-cyano-4-hydroxycinnamic acid to obtain reproducible results. For the younger stages (P2/3 to P10), best results were obtained with methanol $/ \mathrm{H}_{2} \mathrm{O} / \mathrm{TFA}$ (60:39:1), while from P11 up to the adult stage methanol/ethanol/ $\mathrm{H}_{2} \mathrm{O} / \mathrm{TFA}(30: 30: 39: 1)$ turned out to be optimal. Nevertheless, many of the ion signals occurred only in some of the mass spectra obtained from a given developmental stage. Therefore, several spectra were collected for each stage, and the occurrence of ion signals was given as percentage of the total number of measurements for each stage (see S1 in supplementary material). Twelve mass peaks corresponded to known M. sexta peptides (Table 1; Fig. 3). An overview of the relative frequency of occurrence 

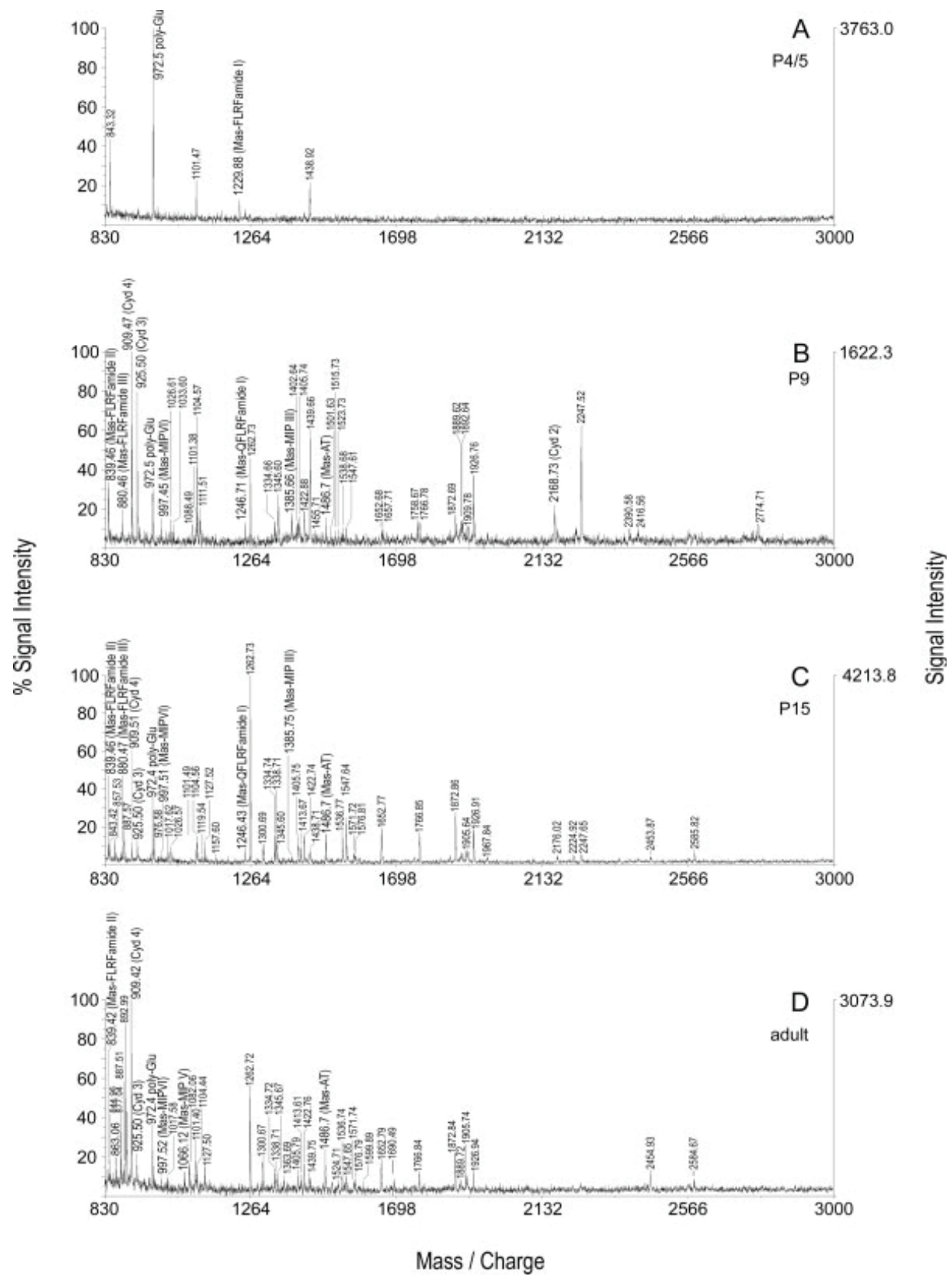

Figure 2 Representative MALDI TOF mass spectra obtained after direct profiling of single lat eral cell groups of the AL of $M$. sexta at different developmental stages. (A) In early pupal stages P2 to P5 spectra of the LC usually contain less than six ion signals ( $n=11$ of 15 evaluated spectra). Mass signal at $m / z 1229.88$ is identical with the mass of FLRFamide I. The mass peak at $m / z$ 972.5, which regularly occurred in spectra of all stages, has been identified via tandem mass spectrometry as an unknown peptide probably ending with poly glutamate (poly Glu, see Fig. 6). (B D) At pupal stage P8, the number of mass peaks measured strongly increased. As revealed by the analysis of 12 ion signals corresponding to known masses in the literature, the pattern of the mass peaks during the rest of development changed however (see text and Fig. 4). Left $y$ axis, relative signal intensity after autoscaling to maximum peak intensity in the selected mass range; right $y$ axis, peak intensity in absolute counts. 
Table 1 Calculated and Measured Monoisotopic Masses $[\mathbf{M}+\mathbf{H}]^{+}$of Identified Peptides in the Lateral Cell Group of Antennal Lobes of M. sexta and their Amino Acid Sequences

\begin{tabular}{llrrrc}
\hline \multicolumn{1}{c}{ Peptide } & \multicolumn{1}{c}{ Sequence } & Calculated & Measured & Mean deviation & Reference \\
\hline Helicostatin 1 & SPHYDFGLa & 934.4 & 934.5 & \pm 0.1 & 1,3 \\
Cydiastatin 2 & AYSYVSEYKRLPVYNFGLa & 2168.1 & 2168.6 & \pm 0.3 & 3,4 \\
Cydiastatin 3 & SRPYSFGLa & 925.5 & 925.5 & \pm 0.1 & $1,3,5$ \\
Cydiastatin 4 & ARPYSFGLa & 909.5 & 909.5 & \pm 0.1 & $1,3,5$ \\
Mas-allatotropin & GFKNVEMMTARGFa & 1486.7 & 1486.7 & \pm 0.1 & $3,8,9$ \\
FLRFamide I & pEDVVHSFLRFa & 1229.6 & 1230.1 & \pm 0.4 & $1,2,7,8$ \\
FLRFamide I ( $\left.{ }^{1}\right)$ & QDVVHSFLRFa & 1246.9 & 1246.7 & \pm 0.1 & $1,2,7$ \\
FLRFamide II & GNSFLRFa & 839.5 & 839.4 & \pm 0.1 & 1,6 \\
FLRFamide III & DPSFLRFa & 880.5 & 880.5 & \pm 0.0 & 1,6 \\
MIP III & APEKWAAFHGSWa & 1385.7 & 1385.7 & \pm 0.1 & 2,4 \\
MIP V & GWQDMSSAWa & 1066.4 & 1066.2 & \pm 0.1 & 2,4 \\
MIP VI & AWSALHGAWa & 997.5 & 997.5 & \pm 0.1 & 1,4 \\
\hline
\end{tabular}

Peptides in bold have been verified in this study by tandem mass spectrometry. Sequences in bold have been verified by Audsley and Weaver (2003b).

(1) Audsley and Weaver, 2003a; (2) Audsley and Weaver, 2003b; (3) Audsley et al., 2005; (4) Blackburn et al., 2001; (5) Duve et al., 1997; (6) Kingan et al., 1997; (7) Kingan et al., 1990; (8) Predel et al., 2003; (9) Kataoka et al., 1989.

is shown in Figure 4. The sequences of cydiastatins 3 and 4, and Mas-AT were verified by fragmentation using MALDI-TOF/TOF MS (data not shown). In contrast to spectra obtained from lateral cell groups, direct profiling of median cell groups at two stages during development (P8, $n=4 ; \mathrm{P} 15, n=2)$ and in adults $(n=2)$ typically revealed no ( 3 of 8 spectra) or only few ion signals ( 5 of 8 spectra) with typically overall very low signal intensity (Fig. 5). Some of the ion signals observed in the spectra of the median cell group were identical to ion signals found in the spectra of lateral cell groups, including FLRFamides I (in 1 of 8 spectra), II (in 2 of 8 spectra), III ( 2 of 8 spectra), Mas-AT (1 of 8 spectra), and some unknown masses, e.g., signals at $m / z 927,1101.5,1338.8$, and 1378.8. The majority of ion signals in the median cell group did not occur in the spectra of the lateral cell group, e.g., $m / z$ 848.3, 1181.7, 1851.2, and 2892.2. MALDI-TOF/TOF fragmentation of the $[\mathrm{M}+\mathrm{H}]^{+}$ion $972.4 \pm 0.1$, which was frequently observed in the lateral as well as in the median cell group, revealed fragments with mass differences of about $129 \mathrm{Da}$, which could indicate a poly-glutamate-containing peptide (Fig. 6).

\section{A-Type Allatostatins}

Four masses corresponding to Y/FXFGL-amide-type allatostatins (A-type-ASTs) were detected in preparations from lateral cell groups of ALs of different developmental stages. In mass spectra of stage P4/5 up to the adults, we obtained ion signals corresponding to cydiastatin 3 [925.5; SRPYSFGLa; Fig. 3(C)] and cydiastatin 4 [909.5; ARPYSFGLa; Fig. 3(C)]. Frag- mentation by MALDI-TOF/TOF MS clearly identified these ions as cydiastatin 3 and 4, respectively (data not shown). In early stages from P4 to P6, detection of cydiastatin 3 and 4 was limited to a few spectra (4 of 14 evaluated spectra for cydiastatin 3 and 6 of 14 evaluated spectra for cydiastatin 4; Fig. 4). From stage P8 onwards, distinct signals of these two peptides could be detected in almost every evaluated mass spectrum for cydiastatin 3 (57 of 59) and cydiastatin 4 [58 of 59; Figs. 2(B D) and 4]. The $[\mathrm{M}+\mathrm{H}]^{+}$ion corresponding to $M$. sexta cydiastatin 2 [2168.1; AYSYVSEYKRLPVYNFGLa; Figs. 2(B) and $3(\mathrm{~B})$ ] occurred in about half of the spectra from preparations of lateral groups between stages P8 and P12 (14 of 29 evaluated spectra), in a single spectrum of a lateral cell group preparation at stage P5 ( 1 of 5 evaluated spectra) and P6 (1 of 4 evaluated spectra), and in two spectra of lateral cell groups of pharate animals (2 of 6 evaluated spectra; Fig. 4). In few spectra (7 of 30 evaluated spectra) obtained from lateral cell groups of P15 and older animals, we detected an ion signal corresponding to the calculated monoisotopic mass of helicostatin 1 [934.4; SPHYDFGLa; Figs. 3(A) and 4].

\section{Mas-Allatotropin}

A weak ion signal at 1486.6 [Fig. 3(D)] that matches with the monoisotopic mass $\left([\mathrm{M}+\mathrm{H}]^{+}\right)$of Mas-AT (1486.7; GFKNVEMMTARGFa) was first detected in a single spectrum in developmental stage P6 (Fig. 4). From stage P8 and throughout the rest of development as well as in the adult stage, a distinct ion signal typical of Mas-AT was measured in most $(n=44)$ of 

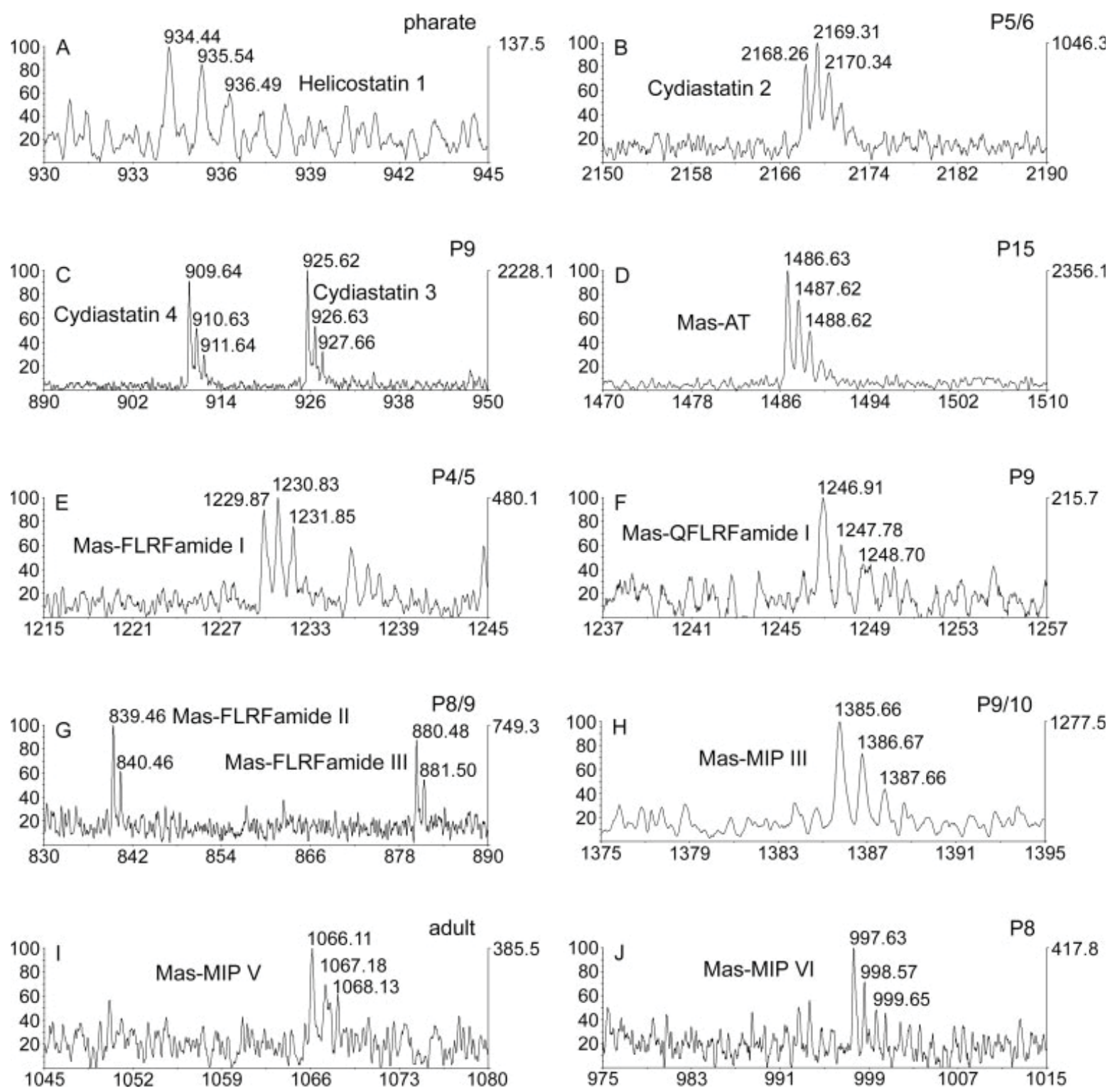

Figure 3 Close ups showing typical examples for the 12 ion signals which matched masses of known neuropeptides after direct profiling of the lateral cell group at different stages. Left $y$ axis, relative signal intensity after autoscaling to maximum peak intensity in the selected mass range; right $y$ axis, peak intensity in absolute counts.

the 59 evaluated spectra [Figs. 2(B D) and 4]. Fragmentation of the $[\mathrm{M}+\mathrm{H}]^{+}$ion at 1486.7 by MALDITOF/TOF confirmed the identity of this substance with Mas-AT (data not shown).

\section{Mas-FLRFamides}

Ion signals corresponding to the calculated monoisotopic masses $\left([\mathrm{M}+\mathrm{H}]^{+}\right)$of Mas-FLRFamide I (1229.6; pEDVVHSFLRFa; 11 of 78 evaluated spectra), Mas-FLRFamide II (839.5; GNSFLRFa; 23 of
78 evaluated spectra), and Mas-FLRFamide III (880.5; DPSFLRFa; 29 of 78 evaluated spectra) were found in mass spectra of lateral cell group preparations of different stages throughout pupal development and in adults (Fig. 4). Signal intensities have been low [Fig. 3(E,G)]. Additionally an ion signal corresponding to the $[\mathrm{M}+\mathrm{H}]^{+}$of Mas-FLRFamide I with an unblocked $\mathrm{N}$-terminus was present in 31 of the 78 evaluated spectra during whole study [1246.7; QDVVHSFLRFa; Figs. 2(B,C), 3(F), and 4]. The frequency of occurrence for Mas-FLRFamides II and III 


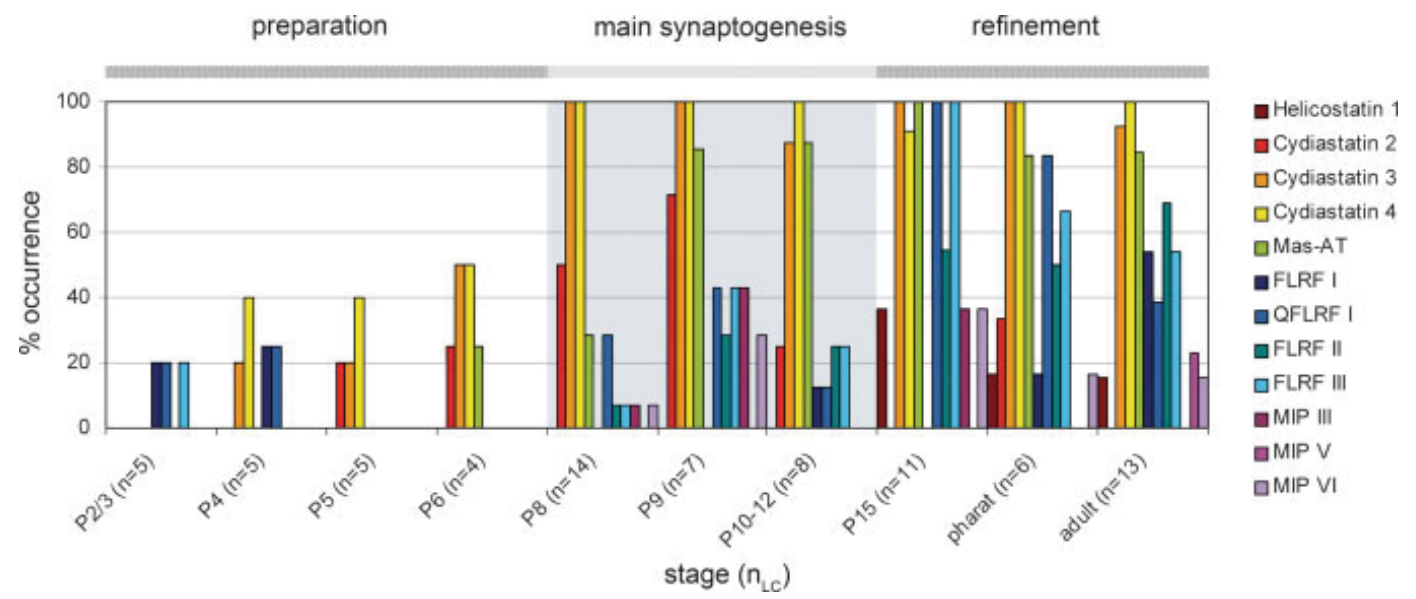

Figure 4 Relative frequency of occurrence of the 12 masses (color coded) matching identified peptides during development. At stage $\mathrm{P} 8$, which marks the beginning of formation of the olfactory glomeruli, the number and frequency of ion signals representing masses of the twelve identified peptides clearly increases in contrast to earlier stages. Analysis of the 12 ion signals revealed that the pattern of mass peaks during development was changing. Cydiastatin $2(\mathrm{~m} / \mathrm{z} 2168.73)$ primarily occurs between stage P8 and P12, while cydiastatins 3 and 4 occurred throughout development and in the adult. Helicostatin 1 occurred only in the spectra of adult animals. FLRFamides occurred throughout development and in the adult, with FLRFamide II not appearing before P8. Myoinhibi tory peptide III (MIP III) exclusively occurred between stages P8 and P15, while MIP V occurred exclusively in the spectra of the lateral cell group of adult animals. For further explanation see text and compare with Figure 2; n, number of analyzed lateral cell groups.

was highest in the spectra of stage P15, pharates and adults ( $\geq 50 \%$ of evaluated spectra). Nonblocked Mas-FLRFamide occurrence was highest in the spectra of stage P15 and pharates (100 and $\geq 80 \%$, respectively). The ion signal corresponding to MasFLRFamide I occurred with highest frequency in adult spectra.

\section{Mas-Myoinhibitory Peptides}

Three masses corresponding to myoinhibitory peptides were detected in lateral cell groups between stage P8 and adult. A monoisotopic mass corresponding to the calculated monoisotopic mass $\left([\mathrm{M}+\mathrm{H}]^{+}\right)$of MasMIP III [1385.7; APEKWAAFHGSWa; Figs. 2(B,C), $3(\mathrm{H})$, and 4] was measured at stage P8 (1 of 14 evaluated spectra), P9 (3 of 7 evaluated spectra), and P15 (4 of 11 evaluated spectra). In contrast, signals for Mas-MIP V (1066.4; GWQDMSSAWa) were observed in the adult stage exclusively [3 of 13 evaluated spectra; Figs. 2(D), 3(I), and 4]. The $[\mathrm{M}+\mathrm{H}]^{+}$ ion 997.6 [Fig. 3(J)] is in agreement with the $[\mathrm{M}+\mathrm{H}]^{+}$signal of myoinhibitory peptide Mas-MIP VI (997.5; AWSALHGAWa) and occurred occasionally in single spectra of different stages starting at stage P8 up to the adult stage [10 of 59 evaluated spectra; Figs. 2(B D), 3(J), and 4].

\section{DISCUSSION}

Direct peptide profiling of a selected cell group (lateral cell group) in a defined region of the brain (the AL) of the sphinx moth M. sexta by MALDI-TOF MS during metamorphosis and in the adult revealed a total of about 100 different mass peaks in the mass range of $8303000 \mathrm{Da}$, suggesting the presence of a substantial number of different neuropeptides. Single spectra of lateral cell groups of animals of stage P8 or older contained a maximum of over 50 ion signals. In contrast, direct profiling of another identified cell group (median cell group) resulted in no or only few ion signals in the obtained spectra. Some of the ion signals observed in the median cell group could also be found in the lateral cell group, but typically the signal intensity was much lower in the spectra of the median cell group compared with the lateral cell group (compare Figs. 2 and 5). As we, in addition to the median cell group, dissected small pieces of glomerular tissue, one source for the ion signals occurring in the median cell group could be contamination stemming from peptidergic neurons of the lateral cell group projecting into the glomerular neuropil. Contamination is supported by the fact that we never detected any immunostaining with antisera against various neuropeptides (including antisera against A- 


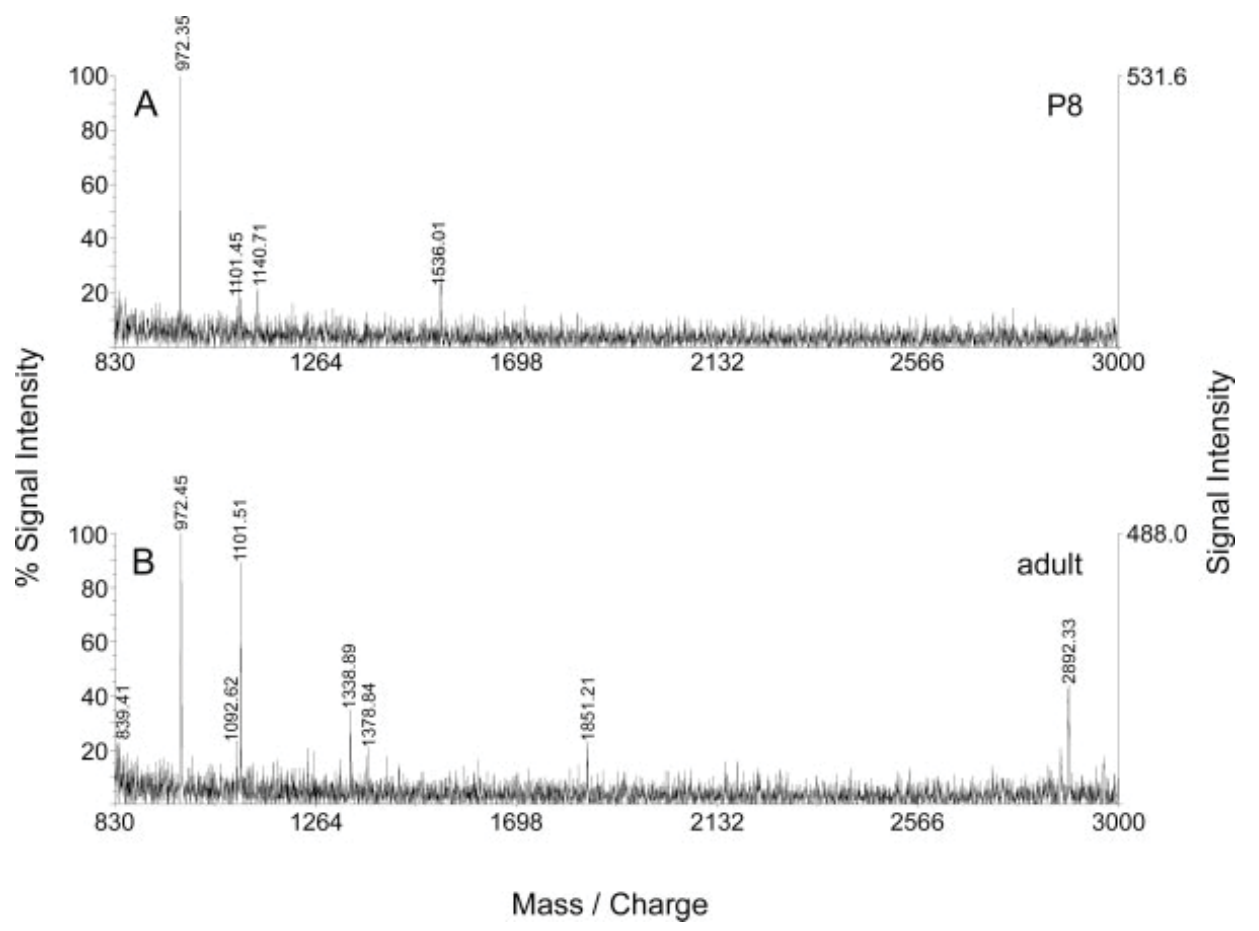

Figure 5 MALDI TOF mass spectra obtained after direct profiling of single median cell groups of the AL of M. sexta at stage P8 (A) and of a freshly eclosed adult animal (B). Spectra obtained af ter direct profiling of the median cell group usually resulted in no or a few ion signals. Similar ion signals could also be measured in lateral cell groups, e.g., in (B) ion signals at $\mathrm{m} / \mathrm{z} 839.4$ (corre sponds to Mas FLRFamide II), 972.4, 1101.5, and 1338.8 (compare with Figs. 2 and 6). Left $y$ axis, relative signal intensity after autoscaling to maximum peak intensity in the selected mass range; right $y$ axis, peak intensity in absolute counts.

type allatostatins, Mas-AT, RFamides, and MIPs) in the median cell group of developing or adult $M$. sexta (Schachtner et al., 2004b; Utz and Schachtner, 2005; Utz et al., 2005; Utz et al., unpublished). However, the majority of the ion signals occurring in the spectra of the median cell group were not present in that of the lateral cell group and represent unknown masses. These ion signals might represent so far unknown peptides or other substances, similar as those observed for the ion signal at $\mathrm{m} / \mathrm{z}$ 972.5.

The ion signals obtained from AL preparations were generally weak; a phenomenon which could indicate a low peptide quantity in these cells. Direct peptide profiling of nervous tissue or single cells in other insects revealed much higher signal intensities (e.g., Ma et al., 2000; Predel et al., 2005, 2006; Berg et al., 2006). The low signal intensity appears thus to be an intrinsic property of $M$. sexta tissue, as also mass spectra obtained by direct profiling of neurohemal organs of $M$. sexta show lower signal intensities than those obtained from homologous organs of other insects (Predel et al., 2003; Predel, unpublished observations). This might not be related to the total amount of peptide present, since even in CNS preparations of very small insects such as Drosophila, direct mass spectrometric profiling yields high inten-

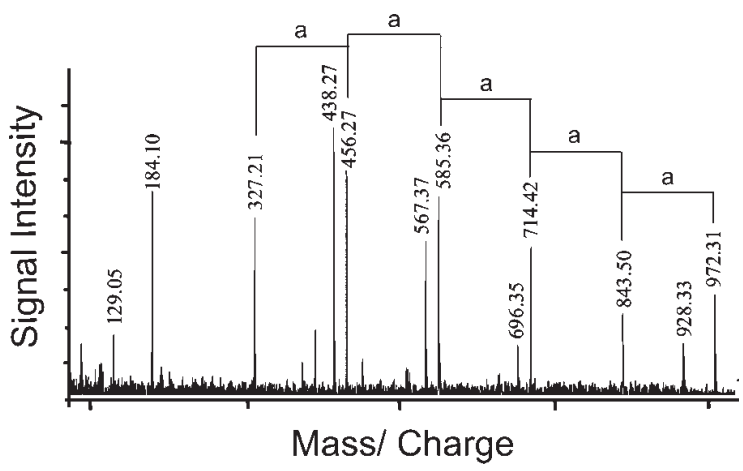

Figure 6 Fragmentation spectrum of the $\mathrm{m} / \mathrm{z} 972.5$ ion signal obtained by tandem mass spectrometry. The constant mass difference of 129 Da suggests the occurrence of a poly glutamate. However, no immonium ions typical of Glu were observed. Thus, it remains unclear if the ion at $\mathrm{m} /$ $z 972.5$ represents a peptide. Note that the mass peak at 184.1 is not substance specific. 
sity peptide signals (Predel et al., 2004). This suggests $M$. sexta-specific endogenous components in the nervous tissue that might prevent optimal cocrystallization of the peptides with the matrix solution or hinder efficient on-target peptide extraction.

\section{Identity of Mass Peaks}

Twelve of the about 100 mass peaks matched neuropeptide masses described in M. sexta or other moths (Table 1). Using tandem mass spectrometry we were able to confirm the identity of three of the more abundant peaks, namely Mas-allatotropin, cydiastatins 3 and 4. Of the remaining nine signals, which indicated the occurrence of known neuropeptides of $M$. sexta, Mas-FLRFamide I was verified by post-source decay using extracts of retrocerebral complex and larval nervous tissue by Audsley and Weaver (2003a,b). The other peptide signals have been shown to occur in mass spectrometric analyses of M. sexta retrocerebral complex, larval nervous tissue, perisympathetic organs and frontal ganglion, but are so far not verified by tandem mass spectrometry (Table 1, Audsley and Weaver, 2003a,b; Predel et al., 2003; Audsley et al., 2005). The four Mas-FLRFamides, three Mas-MIPs, and Mas-AT have been isolated from M. sexta, and their amino acid sequence was characterized (Kataoka et al., 1989; Kingan et al., 1990, 1996; Blackburn et al., 2001). Thus, it can be assumed that these peptides were indeed responsible for the ion signals in the respective mass spectra, particularly since immunocytochemical results indicated the presence of neuropeptides belonging to the above neuropeptide families. Amino acid sequences for helicostatin 1 and cydiastatin 2, however, have so far not been established for M. sexta, and it cannot be excluded that the ion signals at $\mathrm{m} / \mathrm{z} 934.4$ and 2168.3 belong to other substances with identical masses.

\section{Developmental Pattern}

To obtain best results for each developmental stage, we used different solvents for stages P2/3 to P10 and for P11 to adult. Importantly, changes of mass spectrometric profiles became clearly visible within the time window in which we used the same solvents, e.g., from $\mathrm{P} 2 / 3$ to $\mathrm{P} 10 / 12$. After changing the solvent in later stages, this pattern changed only slightly in pupae older than P12. A dramatic change in the composition of the mass peaks would have indicated that a change of solvent influences the mass spectra. As this is not the case, we conclude that solvent changes are not responsible for the mass peak changes observed; hence, what we see are indeed developmental changes.

A-Type Allatostatins. During AL development, ion signals of A-type allatostatins were not detected before stage P4 (Fig. 4). A recent immunocytochemical study revealed over 10 A-type allatostatin-immunoreactive (AST-A-ir) neurons in lateral cell groups of early pupal stages, with the number of immunoreactive neurons rising to over 50 until the onset of phase II (Utz and Schachtner, 2005). Before stage P4, these peptides are obviously present in such low amounts that we could not detect any ion signal. After stage P4, the frequency of occurrence of masses corresponding to cydiastatins 3 and 4 obtained by direct profiling increased until the beginning of phase II (P8). From stage P8 into adulthood, both masses were detected in nearly $100 \%$ of measurements $(57 / 58$ of 59 evaluated spectra for cydiastatin 3 and 4 , respectively). The timing of their appearance may indicate that cydiastatins 3 and 4 play a role during all phases of development and in signal processing in the adult $\mathrm{AL}$. In contrast, the ion signal corresponding to the mass of cydiastatin 2 was mainly concentrated on the transient time period between stage P8 and P10/12 which coincides with phase II the phase of glomeruli formation. This result parallels the finding that during phase II a set of about 15 neurons of the lateral cell group transiently expresses peptides of the Atype allatostatin family (Utz and Schachtner, 2005). Deduced from this parallel, we hypothesize that these $\sim 15$ cells transiently express cydiastatin 2 , which would make the neurons and this neuropeptide good candidates for being involved in the formation of olfactory glomeruli during phase II. It also remains a possibility, however, that the concentration of cydiastatin 2, which normally is below detection threshold, increases with the appearance of additional allatostatin-expressing neurons during phase II, and cydiastatin 2 becomes subsequently detectable.

The ion signal corresponding to helicostatin 1 appeared only in a small percentage of spectra starting in the last part of metamorphosis (P15) up to adulthood. This pattern suggests that helicostatin 1 is merely absent during glomeruli formation, but suggests a possible involvement in processes occurring during phase III and in the adult.

Mas-Allatotropin. Mas-AT was first isolated from heads of pharate adults of M. sexta (Kataoka et al., 1989) and could be identified in the mass spectra of frontal ganglia (Audsley et al., 2005), but not in the retrocerebral complex or larval brain extracts of the same species (Audsley and Weaver, 2003a,b). 
The Mas-AT gene is expressed as at least three mRNA isoforms that differ by alternative splicing and which encode Mas-AT itself and three Mas-AT like peptides (Mas-ATLs; Horodyski et al., 2001). Northern blot analysis revealed that during pupal development only one splice variant, which exclusively contains Mas-AT, is expressed in the brain. In the adult brain additional low levels of a second splice variant, containing Mas-AT and Mas-ATL III, are expressed (Lee et al., 2002). The present study revealed throughout pupal development and in the adult only the ion signal of Mas-AT in the lateral cell group, but no signal corresponding to the predicted mass of Mas-ATL III. This suggests that the splice form containing Mas-AT and Mas-ATL III is either not expressed in the adult ALs or the concentration of Mas-ATL III was too low for being detected.

Mas-AT immunoreactive cell bodies localize to the lateral but not to the median cell group (Fig. 1). In the present study, the earliest ion signal corresponding to Mas-AT was detected at stage P6. From stage P8 onwards, the frequency in the appearance of the Mas-AT ion signal increased and reached a maximum of nearly $100 \%$ at stage P10/12. This corresponds to the finding that two Mas-AT immunoreactive somata are present in early pupae, with numbers increasing to about 100 from stage P6 to P12. The presence of Mas-AT shortly before and during formation of the glomeruli makes this peptide an additional candidate molecule involved in AL development during phases II and III (Utz et al., 2005; Utz et al., in preparation).

Mas-FLRFamides. Ion signals typical of MasFLRFamides have been observed throughout development. Signal intensities obtained for these ions, however, were relatively low as was their frequency of occurrence especially in the stages before P15. Owing to the small intensities, the FLRFamide ion signals could have easily been masked by larger peaks, which could explain the relative low frequency of their occurrence in the various measurements. Additionally, a general low amount of FLRFamides could also be responsible for the low frequency. The latter is suggested by an immunocytochemical study with an antiserum recognizing RFamides (Schachtner et al., 2004b) which revealed few immunoreactive neurons in the lateral cell group during early development. Numbers of immunoreactive cells increased then twice, in a first step up to about 30 neurons at the onset of phase II, and in a second step starting at about P12/13 to reach about 50 cells at stage P15. Thus, the higher reliability for the FLRFamide ion signals starting at P15 could be explained by the higher amount of the peptides, reflected by more cells expressing them.

In $M$. sexta it is assumed that Mas-FLRFamides I III are encoded by three different genes ( $\mathrm{Lu}$ et al., 2002). In situ hybridization revealed that FLRFamide I (F10 according to the authors' nomenclature) is newly expressed in at least $12 \mathrm{AL}$ neurons during metamorphosis (Lu et al., 2002). With this study we confirm these in situ results, and additionally demonstrate the presence of three additional FLRFamides. The presence of more than one FLRFamide in the developing AL has already been postulated earlier (Schachtner et al., 2004b).

Myoinhibitory Peptides. In $M$. sexta, six myoinhibitory peptides (MIP I VI) have been described, which are assumed to be encoded by a single gene (Blackburn et al., 1995, 2001). Similar to the FLRFamides, intensity and frequency of ion signals corresponding to MIP III, V, and VI were low in comparison to signals of, e.g., cydiastatins. The low frequency could be explained by larger mass peaks masking the low intensity MIP signals. Immunostaining with the PeaMIP antiserum, which is thought to generally recognize myoinhibitory peptides, revealed about 60 somata in the lateral cell groups of adults (Huetteroth and Schachtner, unpublished). This number of PeaMIP-ir neurons was already reached early during pupal development. Ion signals corresponding to MIP III and VI occurred not before P8, while MIP V signals occurred only in the adult. Comparison of these mass spectrometric data with the immunostainings suggests that, additionally, other so far unknown myoinhibitory or myinhibitory-related peptides are labeled with the Pea-MIP antiserum. Thus, ion signals of unknown peptides occurring in spectra of the lateral cell group during phase I could possibly account for these unknown myoinhibitory peptides.

Developmental Regulation. The developmental time window, during which the numbers of mass peaks within the lateral cell group dramatically increase, coincides with the onset of the formation of the olfactory glomeruli at stage P7/8 (Figs. 2 and 4). Formation of the glomeruli is under control of the rising titer of the developmental hormone 20-hydroxyecdysone, as is the number of cells in the lateral cell group immunoreactive to neuropeptide antisera including anti-RFamide, anti-allatostatin (A-type), and antiMas-AT (Schachtner et al., 2004b; Utz and Schachtner, 2005; Utz et al., 2005; Utz et al., in preparation). This strongly suggests that the rising hormone titer is causative for the expression of the neuropeptides. Further studies are on their way to reveal whether 
neuropeptide expression is under direct or indirect control of 20-hydroxyecdysone.

In summary, mass spectrometric analysis of neuropeptides of the lateral cell group during AL development suggests a differential occurrence of neuropeptide isoforms encoded either altogether on one gene (A-type allatostatins, Mas-AT, MIPs), or on different genes (FLRFamides). To the best of our knowledge, this is the first mass spectrometric verification of a changing peptide complement in an identified cell group during ontogeny.

The differential expression pattern of individual neuropeptides during AL development suggested in this study clearly supports previous immunocytochemical studies which mapped neuropeptide immunoreactivity during AL ontogeny in the sphinx moth. Most importantly, this study chemically identified neuropeptides and characterized their temporal expression pattern, thus establishing them as candidate molecules involved in the regulation of AL development. We favor the idea that the described neuropeptides might be involved in both the formation of the AL network as well as adult signal processing. It may yet also be possible that the temporal expression pattern of neuropeptides simply is a consequence of AL development, with neuropeptides only serving a function in adult odor processing (Winther et al., 2006).

In any case, the chemical identification of single neuropeptides at defined phases of development allows now to specifically investigate the possible roles and developmental significance of these neuropeptides during the formation of the AL neuronal network.

The authors thank Drs. H. Agricola and M. Eckert (both University of Jena, Germany), E. Buchner (University of Würzburg, Germany), K. Menon (Caltech, USA), J. Veen stra (University of Bordeaux, Talence, France) for kindly providing the various antisera used in this study. We also thank Lotte Søgaard Andersen (Max Planck Institute of Terrestrial Microbiology, Marburg) and Olaf Scheibner (Hans Knöll Institut, Jena) for the use of the MALDI TOF and the Ultraflex TOF/TOF mass spectrometers.

\section{REFERENCES}

Audsley N, Matthews J, Weaver RJ. 2005. Neuropeptides associated with the frontal ganglion of larval Lepidop tera. Peptides 26:11 21.

Audsley N, Weaver RJ. 2003a. A comparison of the neuro peptides from the retrocerebral complex of adult male and female Manduca sexta using MALDI TOF mass spectrometry. Regul Pept 116:127 137.
Audsley N, Weaver RJ. 2003b. Identification of neuropepti des from brains of larval Manduca sexta and Lacanobia oleracea using MALDI TOF mass spectrometry and post source decay. Peptides 24:1465 1474.

Bell RA, Joachim FA. 1978. Techniques for rearing labo ratory colonies of the tobacco hornworm. Manduca sexta, and pink ballworms. Ann Entomol Soc Am 69: 365373

Berg BG, Galizia CG, Brandt R, Mustaparta H. 2002. Digi tal atlases of the antennal lobe in two species of tobacco budworm moths, the oriental Helicoverpa assulta (male) and the American Heliothis virescens (male and female). J Comp Neurol 446:123 134.

Berg BG, Schachtner J, Utz S, Homberg U. 2006. Distribu tion of neuropeptides in the primary olfactory center of the heliothine moth Heliothis virescens. Cell Tissue Res 327:385 398 .

Billimoria CP, Li L, Marder E. 2005. Profiling of neuropep tides released at the stomatogastric ganglion of the crab Cancer borealis with mass spectrometry. J Neurochem 95:191 199.

Blackburn MB, Jaffe H, Kochansky J, Raina AK. 2001. Identification of four additional myoinhibitory peptides (MIPs) from the ventral nerve cord of Manduca sexta. Arch Insect Biochem Physiol 48:121 128.

Blackburn MB, Wagner RM, Shabanowitz J, Kochansky JP, Hunt DF, Raina AK. 1995. The isolation and identifi cation of three diuretic kinins from the abdominal ventral nerve cord of adult Helicoverpa zea. J Insect Physiol 41:723 730 .

Caillol M, Aioun J, Baly C, Persuy MA, Salesse R. 2003. Localization of orexins and their receptors in the rat ol factory system: Possible modulation of olfactory percep tion by a neuropeptide synthesized centrally or locally. Brain Res 960:48 61.

Dubuque SH, Schachtner J, Nighorn AJ, Menon KP, Zinn K, Tolbert LP. 2001. Immunolocalization of synap totagmin for the study of synapses in the developing antennal lobe of Manduca sexta. J Comp Neurol 441: 277287.

Duve H, Johnsen AH, Maestro JL, Scott AG, Winstanley D, Davey M. 1997. Lepidopteran peptides of the allatos tatin superfamily. Peptides 18:1301 1309.

Eisthen HL. 2002. Why are olfactory systems of different animals so similar? Brain Behav Evol 59:273 293.

Gutierrez Mecinas M, Crespo C, Blasco Ibanez JM, Gracia Llanes FJ, Marques Mari A, Martinez Guijarro. 2005. Characterization of somatostatin and cholecystokinin immunoreactive cells in the rat olfactory bulb. J Comp Neurol 489:467 479.

Hildebrand JG. 1985. Metamorphosis of the nervous sys tem: Influence of the periphery on the postembryonic de velopment of the antennal sensory pathway in the brain of Manduca sexta. In: Selverston A, editor. Model Neural Networks and Behavior. New York: Plenum, pp 129148.

Hildebrand JG, Rössler W, Tolbert LP. 1997. Postem bryonic development of the olfactory system in the moth Manduca sexta: Primary afferent control of glomerular development. Cell Dev Biol 8:163 170. 
Hildebrand JG, Shepherd GM. 1997. Mechanisms of olfac tory discrimination: Converging evidence for common principles across phyla. Annu Rev Neurosci 20:595 631.

Homberg U, Montague RA, Hildebrand JG. 1988. Anatomy of antenno cerebral pathways in the brain of the sphinx moth Manduca sexta. Cell Tissue Res 254:255 281.

Homberg U, Müller U. 1999. Neuroactive substances in the antennal lobe. In: Hanson BS, editor. Insect Olfaction. Berlin: Springer, pp 181206.

Horodyski FM, Bhatt SR, Lee K Y. 2001. Alternative splic ing of transcripts expressed by the Manduca sexta allato tropin (Mas AT) gene is regulated in a tissue specific manner. Peptides 22:263 269.

Huetteroth W, Schachtner J. 2005. Standard three dimen sional glomeruli of the Manduca sexta antennal lobe: A tool to study both developmental and adult neuronal plas ticity. Cell Tissue Res 319:513 524.

Hummon AB, Richmond TA, Verleyen P, Baggerman G, Huybrechts J, Ewing MA, Vierstraete E, Rodriguez Zas SL, Schoofs L, Robinson GE, Sweedler JV. 2006. From the genome to the proteome: Uncovering peptides in the Apis brain. Science 314:647 649.

Jindra M, Huang JY, Malone F, Asahina M, Riddiford LM. 1997. Identification and mRNA developmental profiles of two ultraspiracle isoforms in the epidermis and wings of Manduca sexta. Insect Mol Biol 6:41 53.

Kataoka H, Toschi A, Li JP, Carney L, Schooley DA, Kramer SJ. 1989. Identification of an allatotropin from adult Manduca sexta. Science 243:1481 1483.

Kingan TG, Shabanowitz J, Hunt DF, Witten JL. 1996. Characterisation of two myotropic neuropeptides in the FMRFamide family from segmental ganglia of the moth Manduca sexta: Candidate neurohormones and neuromo dulators. J Exp Biol 199:1095 1104.

Kingan TG, Teplow DB, Phillips JM, Riehm JP, Rao KR, Hildebrand JG. 1990. A new peptide in the FMRFamide family isolated from the CNS of the hawkmoth Manduca sexta. Peptides 11:849 856.

Lee K Y, Chamberlin ME, Horodyski FM. 2002. Biological activity of Manduca sexta allatotropin like peptides, pre dicted products of tissue specific and developmentally regulated alternatively spliced mRNAs. Peptides 23:1933 1941.

Lu D, Lee KY, Horodyski FM, Witten LJ. 2002. Molecular characterization and cell specific expression of a Man duca sexta FLRFamide gene. J Comp Neurol 446:377 396.

Ma PW, Garden RW, Niermann JT, O' Connor M, Sweedler JV, Roelofs WL. 2000. Characterizing the Hez PBAN gene products in neuronal clusters with immunocyto chemistry and MALDI MS. J Insect Physiol 46:221 230.

Moody TW, Merali Z. 2004. Bombesin like peptides asso ciates receptors within the brain: Distribution and behav ioral implications. Peptides 25:511 520.

Nachman RJ, Russel WK, Coast GM, Russel DH, Miller JA, Predel R. 2006. Identification of PVK/CAP2b neuro peptides from single neurohemal organs of the stable fly and horn fly via MALDI TOF/TOF tandem mass spec trometry. Peptides 27:521 526.

Negoescu A, Labat Moleur F, Lorimier P, Lamarcq L, Guillermet C, Chambaz E, Brambilla E. 1994. F(ab) sec ondary antibodies: A general method for double immu nolabeling with primary antisera from the same species. Efficiency control by chemoluminescence. J Histochem Cytochem 42:433 437.

Neupert S, Predel R. 2005. Mass spectrometric analysis of single identified neurons of an insect. Biochem Biophys Res Commun 327:640 645.

Oland LA, Pott WM, Higgins MR, Tolbert LP. 1998. Tar geted ingrowth and glial relationships of olfactory recep tor axons in the primary olfactory pathway of an insect. J Comp Neurol 398:119 138.

Oland LA, Tolbert LP. 1996. Multiple factors shape devel opment of olfactory glomeruli: Insights from an insect model system. J Neurobiol 30:92 109.

Predel R, Eckert M, Pollák E, Molnár L, Scheibner O, Neupert S. 2006. Peptidomics of identified neurons dem onstrates a highly differentiated expression pattern of FXPRLamides in the neuroendocrine system of an insect. J Comp Neurol 500:498 512.

Predel R, Herbert Z, Eckert M. 2003. Neuropeptides in peri sympathetic organs of Manduca sexta: Specific composi tion and changes during development. Peptides 24:1457 1464.

Predel R, Neupert S, Roth S, Derst C, Nässel DR. 2005. Tachykinin related peptide precursors in two cockroach species. FEBS J 272:3365 3375.

Predel R, Rapus J, Eckert M. 2001. Myoinhibitory peptides in the American cockroach. Peptides 22:199 208.

Predel R, Wegener C, Russell WK, Tichy SE, Russell DH, Nachman RJ. 2004. Peptidomics of CNS associated neu rohemal systems of adult Drosophila melanogaster: A mass spectrometric survey of peptides from individual flies. J Comp Neurol 474:379 392.

Riehle MA, Garczynski SF, Crim JW, Hill CA, Brown MR. 2002. Neuropeptides and peptide hormones in Anopheles gambiae. Science 298:172 175.

Schachtner J, Huetteroth W, Nighorn A, Honegger HW. 2004a. Copper/zinc superoxide dismutase like im munoreactivity in the metamorphosing brain of the sphinx moth Manduca sexta. J Comp Neurol 469: 141152.

Schachtner J, Schmidt M, Homberg U. 2005. Organization and evolutionary trends of primary olfactory brain cen ters in Tetraconata (Crustacea + Hexapoda). Arthropod Struct Dev 34:257 299.

Schachtner J, Trosowski B, D’Hanis W, Stubner S, Homberg U. 2004b. Development and steroid regulation of RFa mide immunoreactivity in antennal lobe neurons of the sphinx moth Manduca sexta. J Exp Biol 207:2389 2400.

Schwartz LM, Truman JW. 1983. Hormonal control of rates of metamorphic development in the tobacco hornworm Manduca sexta. Dev Biol 99:103 114.

Smith RL, Baker H, Greer CA. 1993. Immunohistochemi cal analysis of the human olfactory bulb. J Comp Neurol 333:519 530 . 
Strausfeld NJ, Hildebrand JG. 1999. Olfactory systems: Common design, uncommon origins? Curr Opin Neuro biol 9:634 639 .

Tolbert LP. 1989. Afferent axons from the antenna influ ence the number and placement of intrinsic synapses in the antennal lobes of Manduca sexta. Synapse 3:83 95.

Tolbert LP, Matsumoto SG, Hildebrand JG. 1983. Develop ment of synapses in the antennal lobes of the moth Manduca sexta during metamorphosis. J Neurosci 3:1158 1175.

Tolbert LP, Oland LA, Tucker ES, Gibson NJ, Higgins MR, Lipscomb BW. 2004. Bidirectional influences between neurons and glial cells in the developing olfac tory system. Prog Neurobiol 73:73 105.

Truman JW. 1996. Ecdysis control sheds another layer. Sci ence 271:40 41.

Utz S, Huetteroth W, Schachtner J. 2005. Development and steroid regulation of Mas allatotropin immunostaining in antennal lobe neurons of the sphinx moth Manduca sexta. In the 98th Meeting of the German Zooogical So ciety, Bayreuth, Germany. No. 1 Po 24

Utz S, Schachtner J. 2005. Development of A type allatostatin immunoreactivity in antennal lobe neurons of the sphinx moth Manduca sexta. Cell Tissue Res 320:149 162.

Vanden Broeck J. 2001. Neuropeptides and their precursors in the fruitfly, Drosophila melanogaster. Peptides 22:241 254.
Veenstra JA, Hagedorn HH. 1993. Sensitive enzyme immu noassay for Manduca allatotropin and the existence of an allatotropin immunoreactive peptide in Periplaneta americana. Arch Insect Biochem Physiol 23:99 109.

Vitzthum H, Homberg U, Agricola H. 1996. Distribution of Dip Allatostatin I like immunoreactivity in the brain of the locust Schistocerca gregaria with detailed analysis of immunostaining in the central complex. J Comp Neurol 369:419 437.

Weevers RD. 1966. A lepidopteran saline: The effects of inorganic cation concentrations on sensory reflex and motor responses in a herbiverous insect. J Exp Biol 44: 163176.

Wegener C, Reinl T, Jänsch L, Predel R. 2006. Direct mass spectrometric peptide profiling and fragmentation of larval peptide hormone release sites in Drosophila melanogaster reveals tagma specific peptide expression and differential processing. J Neurochem 96:1362 1374.

Winther ÅME, Acebes A, Ferrus A. 2006. Tachykinin related peptides modulate odor perception and locomotor activity in Drosophila. Mol Cell Neurosci 31:399 406.

Yew JY, Dikler S, Stretton AO. 2003. De novo sequencing of novel neuropeptides directly from Ascaris suum tissue using MALDI TOF/TOF. Rapid Commun Mass Spec trom 17:2693 2698. 